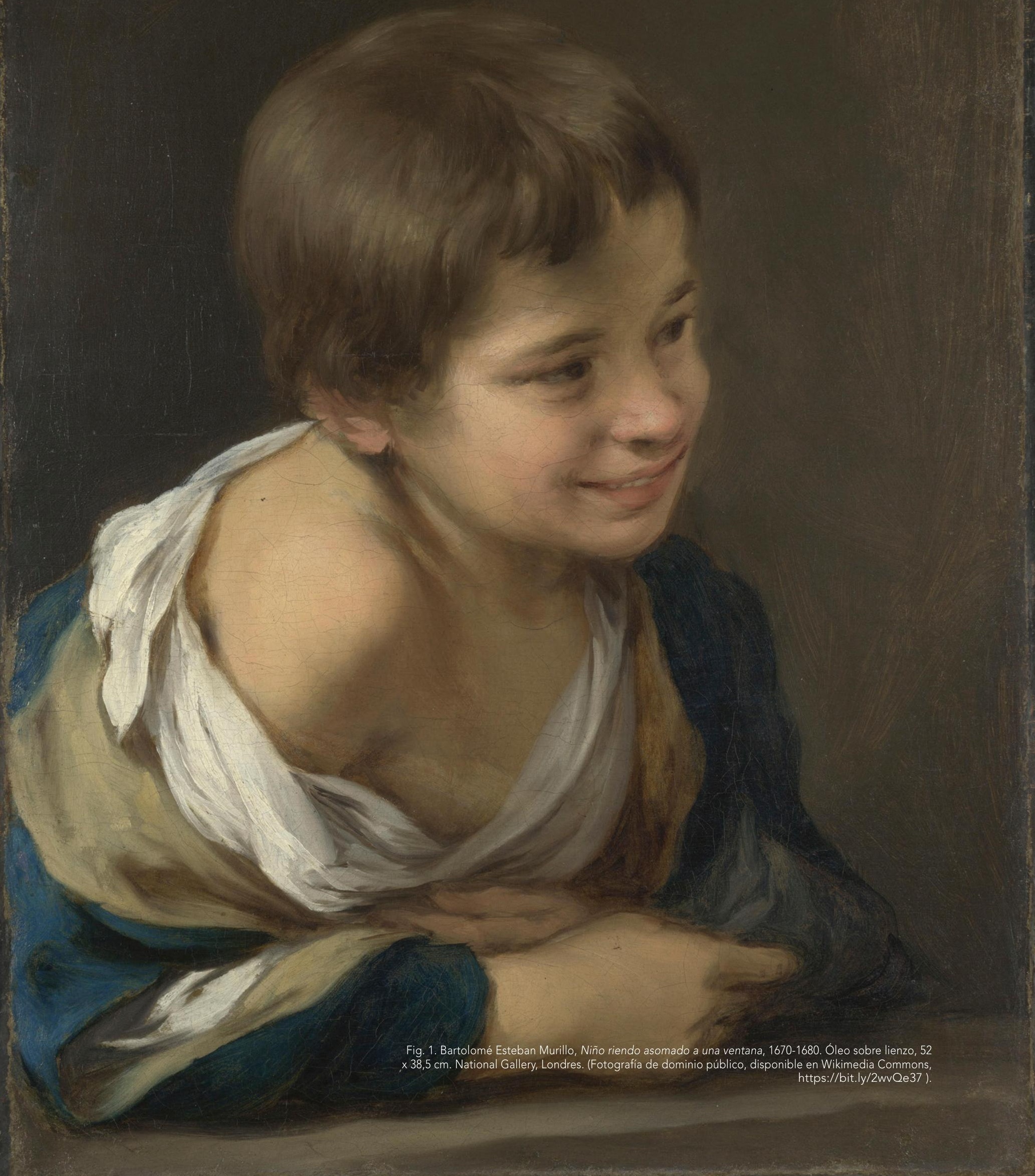




\section{Murillo y el ideal
del sanctus pauper}

Murillo and the Ideal of the Sanctus Pauper

\section{Resumen}

La valoración teológica del mundo de la pobreza, había generado serias controversias doctrinales en el seno de la Iglesia católica desde la Edad Media, e incluso desde los mismos tiempos que dieron origen a la Patrística fundacional.

Más, con el advenimiento de los movimientos reformistas, fundamentalmente de carácter erasmista, la figura del pobre perdería su sentido beatífico, como puente y enlace entre el cristiano y su salvación. Es el momento en que aparece una nueva concepción basada en la propia redención de este en vida a través del trabajo y su regeneración como miembro activo de la sociedad. Sin embargo, con la Contrarreforma
Arsenio Moreno Mendoza

Universidad Pablo de Olavide, Sevilla, España

amormen@upo.es https://orcid.org/0000-0001-9801-618X

Cómo citar este trabajo / How to cite this paper:

Moreno Mendoza, Arsenio. "Murillo y el ideal del sanctus pauper." Atrio. Revista de Historia del Arte, no. 25 (2019): 8-23.

(C) 2019 Arsenio Moreno Mendoza. Este es un artículo de acceso abierto distribuido bajo los términos de la licencia Creative Commons AttributionNonCommercial-ShareAlike 4.0. International License (CC BY-NC-SA 4.0). 
y su apuesta por la práctica de la caridad, volvería a imperar el carácter sagrado de la pobreza y su función insustituible para la salvación del ejercicio de la misericordia.

La pobreza, el pobre, no han sido puestos por Dios ante nosotros para ser ocultados, sino para recordarnos nuestras obligaciones morales y el camino de nuestra salvación. Y es en esta línea donde se inscribe iconológicamente la obra de Murillo: la del ejemplo de la caridad y la pobreza.

Palabras clave: Murillo; pobreza; Sevilla barroca. mercy. Poverty and the pauper have not been put before us by God to be hidden but to remind us of our moral obligations and the road to our salvation; it is in this line that Murillo's work and its iconography come in: an example of charity and poverty.

Keywords: Murillo; poverty; Baroque Sevilla.

La representación del mundo de la pobreza en la pintura europea ofrece variantes de índole cronológico o temporal; más, ante todo, de carácter geográfico y por ende ideológico.

En España prácticamente podemos decir que no existen precedentes de este género pictórico, por lo general moralizante, hasta la segunda década del XVII. No sucedía lo mismo en Italia o Flandes, donde podríamos - entre otros - contar con los ejemplos de un Vincenzo Campi y sus Campesinos comiendo queso (colección privada, Cremona) o Bruegel el Viejo con infinidad de muestras entre las cuales yo destacaría $E l$ vino de la fiesta de San Martín (Museo del Prado, Madrid). Pero también autores como Pieter Aertsen, Joachim Beuckelaer, Joost Cornelisz y sus Mendigos festivos, o Jan Both y su memorable Fiesta en la embajada de España. Cito solamente estos ejemplos, aunque el listado de obras y autores podría convertirse en abrumador.

Son obras que en su momento ya eran definidas como "pitture ridicole," de personajes grotescos y una más que evidente crítica social, crítica sarcástica que recaía sobre la figura del pobre. ${ }^{1}$ Pues el pobre podía llegar a ser la reencarnación de los siete pecados capitales; sobre todo de la gula.

En Sevilla la pintura de género desarrollada por Velázquez en su etapa juvenil no encontró continuidad. Tampoco esta apenas si tuvo precedentes, siendo muy pobres las referencias coetáneas a este género de obras. Francisco López Caro (1598-1662), otro discípulo de Pacheco, en la década de los años veinte imitaba los bodegones de Velázquez — ¿ o era una tendencia más generalizada? - Ambos eran amigos, ambos compartieron pupilaje y taller, aunque no el mismo talento. En cualquier caso es muy poco lo que conocemos de este artista.

Existe constancia de la actividad de Francisco de Herrera el Viejo como pintor de bodegones y escenas de género. De él nos decía Palomino que "tuvo también singular gusto en pintar bodegoncillos con diferentes baratijas de cocina, hechas por el natural, con tal propiedad, que engañan." ${ }^{2}$ Este maestro sevillano

1. Barry Wind, Studies in Genre Painting: 1580-1630 (New York: New York University, 1973).

2. Antonio Palomino de Castro y Velasco, El museo pictórico y escala óptica. Práctica de la pintura, en que se trata del modo de pintar á el olio, temple y fresco con la resolucion de todas las dudas que en su manipulacion pueden ocurrir, y de la perspectiva común, la de techos, ángulos, teatros, y monumentos de perspectiva, y otras cosas muy especiales, con la direccion y documentos para las ideas ó asuntos de las obras de que se ponen algunos ejemplares (Madrid: Imprenta de Sancha, 1797), 2:468. 
nos ha dejado un excepcional cuadro, El músico ciego y su lazarillo, del Kunsthistorisches Museum de Viena, pintado hacia 1645. Se trata de una composición de medias figuras, el ciego que guiado por un muchacho pide limosna acompañado de su zanfońa. Sobra aquí hablar de resonancias literarias.

Ceán confirmaba esta faceta pictórica de Herrera cuando afirmaba que "son muy apreciables los bodegoncillos de su mano, que hay muchos en Sevilla," aunque se lamenta — de un modo contradictorio— de "que hoy son muy raros, por haberlos llevado los extranjeros." ${ }^{3}$ De hecho, la colonia de mercaderes flamencos de Sevilla qué duda cabe que gustaba de este tipo de obras. Nicolás Omazur, uno de los grandes mecenas de Murillo, poseía un cuadro tan emblemático como la Vieja friendo huevos de Velázquez, tal como se desprende de su inventario de bienes realizado en $1698 .{ }^{4}$

En cualquier caso estos cuadros representan escenas protagonizadas por pocos personajes, casi siempre extraídos de un universo humilde, pobre, que se desenvuelven en espacios cerrados, de una sobriedad metafísica. Hablamos de una representación neutral y yo diría que indiferente a cualquier juicio de valor. Sus protagonistas, siendo humildes, no tienen porqué enfatizar ninguna virtud, pero tampoco lo contrario.

¿Qué ha sucedido para que en una misma ciudad, tan solo una generación posterior, un maestro como Murillo afronte este mundo de la pobreza, no ya sin el más mínimo reproche o salvedad moral, sino con verdadera complacencia por el pobre?

Murillo frente al espacio cerrado nos devuelve la luz de la calle. Y esto es lo que ya antes habían hecho los bamboccianti en Roma. Enclaves urbanos populares, visiones de una vida cotidiana vinculada a una población pobre pero aparentemente feliz, desenfadada, grotesca, alegre. Es el pueblo meridional que hace del espacio urbano el escenario habitual de sus vidas. ${ }^{5}$

Este tipo de pintura no está pensada, al menos exclusivamente, para acompañar a su regreso al peregrino o el viajero internacional que visita Roma; en Flandes u Holanda también encuentra un mercado de importación más que notable. Su influencia llegó a Sevilla como lo manifiesta una obra de Ignacio de Iriarte El vado (Museo Hermitage, San Petersburgo), donde las referencia a Pieter van Laer o Claes Pietersz son evidentes. Tampoco son ajenos a esta corriente los abocetados paisajes de Francisco Antolínez, poblados de pequeñas y alegres figuras. ${ }^{6}$

Parece más que probable que Murillo tuviera acceso a la contemplación de obras de Pieter van Laer o Michelangelo Cerquozzi, pues su buen amigo y mecenas Joshua van Belle, poseía cuadros de ambos maestros. También el duque de Alcalá, tal como se desprende del inventario de su almoneda, fechado en Génova en 1637, era propietario de una docena de lienzos de Pieter van Laer, pintor que un año antes había dedicado una serie de seis láminas a su aristocrático protector. Cerquozzi y Van Laer habían mantenido una productiva relación con los círculos españoles de Roma. Su pintura, por tanto, era conocida en Sevilla.

\footnotetext{
3. Juan Agustín Ceán Bermúdez, Diccionario Histórico de los más ilustres profesores de las Bellas Artes en España (Año de 1800) (Madrid: Imprenta de la Viuda de Ybarra, Edición facsímil, 1965), 2:277.

4. William B. Jordan y Peter Cherry, El bodegón español de Velázquez a Goya (Madrid: El Viso, 1995), 41.

5. David A. Levine y Ekkehard Mai, I Bamboccianti: Niederländische Malerrebellen im Rom des Barock (Köln: Wallraf-Richartz Museum, 1991).

6. Arsenio Moreno Mendoza, Mentalidad y pintura en la Sevilla del Siglo de Oro (Madrid: Electa, 1997), 101.
} 


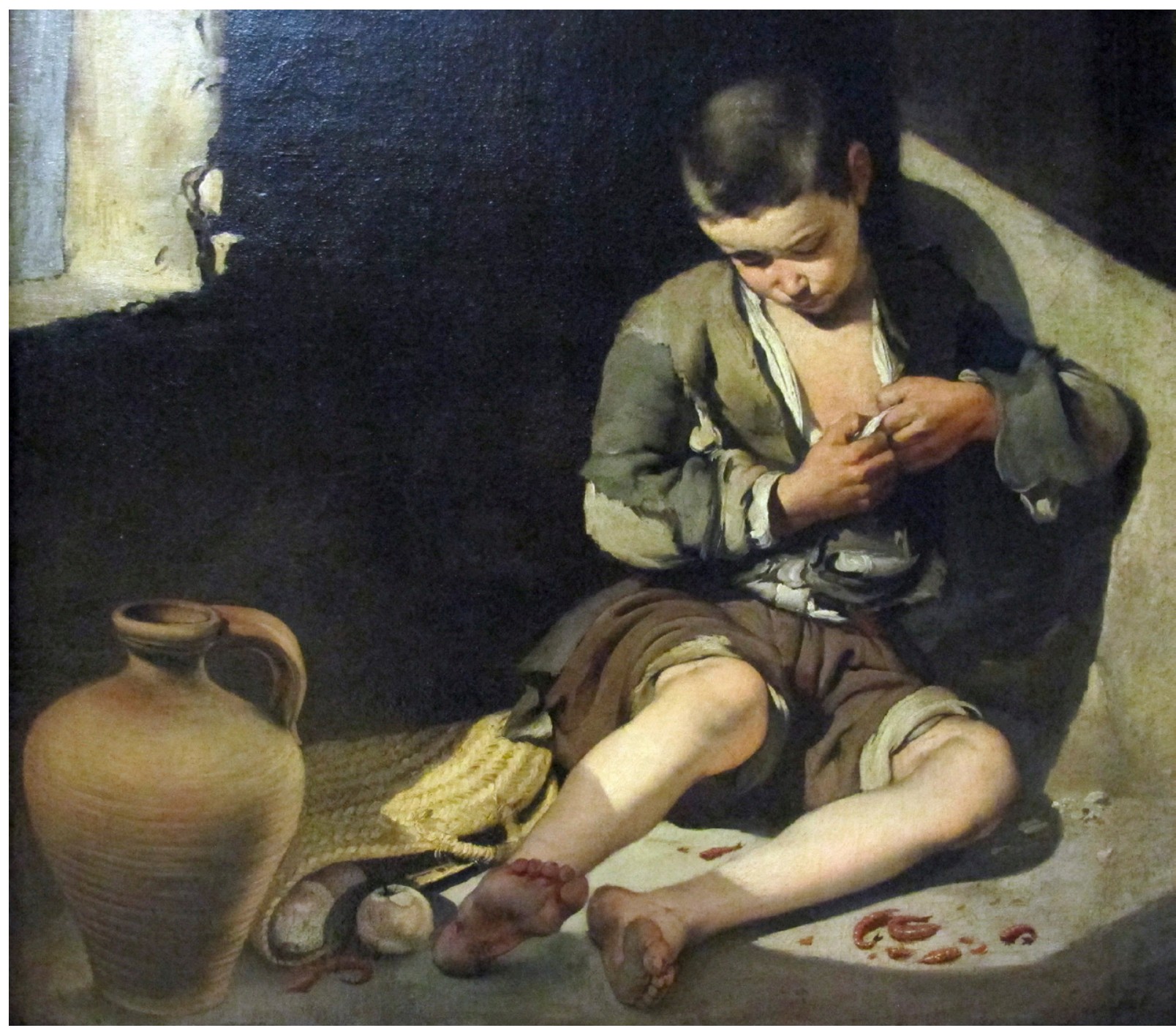

Fig. 2. Bartolomé Esteban Murillo, Joven mendigo, 1645-1650. Óleo sobre lienzo, 137 x 115 cm. Musée du Louvre, París. (Fotografía de Sailko, disponible en Wikimedia Commons, https://bit.ly/2xqzTg6).

Otro pintor vinculado a este tipo de producción artística es el danés Eberhardt Keil, o "Monsu Bernardo," como era conocido entre los artistas nórdicos de la Ciudad Eterna. Nacido en Elsinor en 1624 y formado en Ámsterdam junto a Rembrandt, marcha a Italia en 1651 donde, tras recorrer ciudades como Venecia, Bérgamo, Milán, Forli o Rávena, acaba estableciéndose en Roma en 1661 hasta su fallecimiento en 1687. En la capital italiana Keil practicaría un prototipo de pintura especializada en escenas de vida popular, cuyos protagonistas son nińos, maestros de escuela, leñadores, pobres y ancianos.

Gracias a Baldinucci, su biógrafo, sabemos que este artista envió obras a España: "Mando assai pitture in Francia; molte altresi in Ispagna e particularmente due grandi quadri d'un San Paolo primo eremita e di un San Gerolano." Las correspondencias entre las obras de Murillo con las del danés son sostenibles. ¿Llegó nuestro maestro a conocer algunas de estas pinturas? Pérez Sánchez así lo sospechaba: 


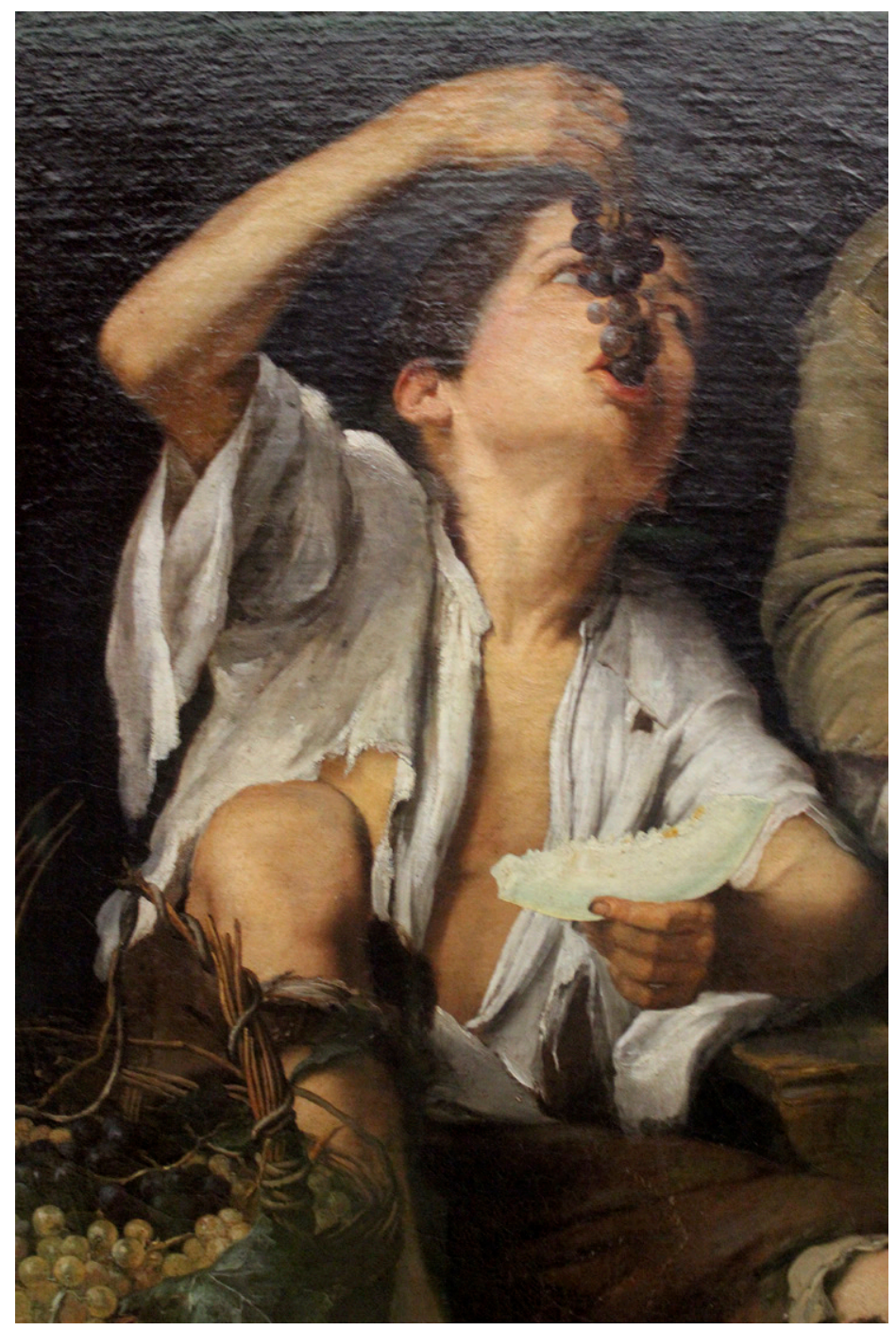

Fig. 3. Bartolomé Esteban Murillo, Niños comiendo uvas y melón (detalle), ca. 1650. Óleo sobre lienzo, 145,6 × 103,6 cm. Alte Pinakothek, Múnich. (Fotografía de Miguel Hermoso Cuesta, disponible en Wikimedia Commons,

https://commons.wikimedia.org/wiki/File:Muchachos_comiendo_Murillo_Munich.jpg ).

Su presencia en España puede resultar bien interesante para la definitiva cristalización de un tipo de cuadro de género, del cual Murillo (de vida casi paralela, en el tiempo, a la de nuestro Keil) es el más grande representante. Recuérdese que buena parte de estos cuadros de género fueron tenidos por españoles, y si bien la atribución a Velázquez quedaba fuera de lugar, la de $\mathrm{Mu}$ rillo o Villavicencio no andaba, al menos cronológicamente, tan descabellada. ${ }^{7}$

Pérez Sánchez nos dio a conocer en 1961 cinco nuevos lienzos de Keil existentes en diversas colecciones españolas. Son obras de iconografía popular, de pincelada larga y espesa, de vigorosos rostros y plegados. No obstante, Angulo no dejaba de comentar que el estilo de Keil es "un tanto pesadote, de rebuscadas actitudes, interesado por lo característico, e inclinado a dar expresiones en general adustas." ${ }^{\text {En }}$ una palabra, carente de la espontaneidad y la brillantez de las creaciones murillescas.

También Brown señaló en su momento las relaciones existentes entre el pintor sevillano y el flamenco Michael Sweerts (16241664), artista activo en Roma entre los ańos 1646 y 1652 . Maestro de la vida cotidiana, sus temas ofrecen —en palabras de Brown - un enfoque elegiaco, "con sus humildes personajes que tienen un aire irreal." 9

Ninguna de estas posibles relaciones entre artistas son fáciles de demostrar y menos de un modo específico.

Naturalmente que la pintura de género de Murillo habría de encontrar en la colonia de extranjeros residentes en Sevilla una de sus más sólidas clientelas. Peter Wouter había adquirido del maestro en 1673 dos de sus cuadros de mendigos. Otro comerciante, J.B. Anthoine dejaba a su muerte, antes de que acabara el

\footnotetext{
7. Alfonso Emilio Pérez Sánchez, "Algunas obras de 'Monsu Bernardo'," Archivo Español de Arte 34, no. 134 (1961): 143.

8. Diego Angulo Íñiguez, "Murillo, su vida y su obra," en Bartolomé Esteban Murillo 1617-1682, coords. Manuela B. Mena Marqués y M. ${ }^{2}$ Isabel de Alzaga de Serra (Madrid: Museo del Prado, 1982), 73. Publicado en conjunto con una exhibición del mismo título, organizada y presentada en el Museo del Prado en Madrid, 8 de octubre de 1982-12 de diciembre de 1982, y en la Royal Academy of Arts en Londres, 15 de enero de 1983-27 de marzo de 1983.

9. Jonathan Brown, "Murillo, pintor de temas eróticos: Una faceta inadvertida de su obra," Goya: Revista de Arte, no. $169-171$ (1982): 38.
} 
siglo, un original y dos copias del pintor. ${ }^{10}$ De sobra es conocida — ya reiterada — su amistad con hombres de negocios como Nicolás Omazur y Joshua van Belle, ávidos coleccionistas de su obra.

Pero la pintura de género de Murillo y mucho más su representación del sugerente mundo de la pobreza se nos presenta en otro horizonte que nada tiene que ver con este tipo de representaciones de origen septentrional. No hablo solo de su extremada calidad técnica, su prodigioso dominio de la luz "vaporosa" y etérea, el color deslumbrante, la plasmación aérea del espacio, el maravilloso dibujo, la gestualidad contenida y verosímil de sus imágenes... Me refiero a lo que recientemente Benito Navarrete ha definido como la empatía amorosa que su obra trasmite al espectador de su obra. ${ }^{11} \mathrm{Y}$ también su extremada alianza con el pensamiento contrarreformista más ortodoxo y militante de la época. Y es aquí donde interviene de forma inequívoca su visión de la pobreza y su expresión y representación en el lienzo como un persuasivo sermón doctrinal, comprometido y distorsionador.

A lo largo de todo el Antiguo Régimen ¿̨había sido España el único país de Occidente — se preguntaba Bartolomé Bennassar - que había continuado siendo fiel a la concepción medieval, y por tanto evangélica, de la pobreza. ${ }^{12}$ Ya podemos anticipar que no, que las disputas teológico-morales, el debate reformista, sobre esta materia adquirió un extraordinario calado sobre todo hasta los últimos años del siglo XVI. De la misma manera que sería la visión más conservadora la que habría de obtener una victoria más aplastante. Y a esa victoria se sumaba Bartolomé Esteban Murillo.

Para el cristianismo medieval el pobre era el sanctus pauper, o lo que es igual, aquella persona querida por Dios y reverenciada en cuanto imagen providencial de Jesucristo en la Tierra. La caridad, por tanto, sin distinguir entre mendigos falsos o legítimos, era un privilegio de los pobres y un deber sagrado para los ricos. ${ }^{13}$ La pobreza en los siglos medievales no era considerada una lacra social, sino una gracia divina que posibilitaba al rico su salvación eterna a través de la limosna. Por lo demás esta teoría era defendida por buena parte de los Padres de la Iglesia como san Agustín, san Ambrosio, san Cipriano o san Juan Crisóstomo. ${ }^{14}$

Trento, frente a los postulados protestantes, dejó bien clara esta premisa: "Sola la fe con obras salva." Sin embargo, en países como Francia, Inglaterra o España, ya a mediados del siglo XIV y fruto de la peste negra y la ausencia de mano de obra, se comenzaban a establecer medidas represivas contra el vagabundo y el pobre mendicante. Por primera vez la pobreza se empieza a tildar de vicio y la vagancia de delito.

Esta actitud se irá radicalizando en el Renacimiento con adalides intelectuales como Erasmo y su Elogio de la locura de 1511, o Tomás Moro y su Utopía, 1516. Había comenzado el proceso de desacralización de los pobres de la mano de una áspera crítica a la rapacidad de los frailes mendicantes. Un proceso que concluiría de un modo inevitable con la obra de Lutero y el advenimiento de la Reforma. A partir de este momento la brecha abierta entre ambas mentalidades, entre ambas geografías, norte y sur, se iría haciendo más profunda.

\footnotetext{
10. María de los Santos García Felguera, La Fortuna de Murillo (Sevilla: Diputación Provincial, 1989), 34.

11. Benito Navarrete Prieto, Murillo y las metáforas de la imagen (Madrid: Cátedra, 2017).

12. Bartolomé Bennassar, La España del Siglo de Oro (Barcelona: Ed. Crítica, 2017), 203.

13. María Jiménez Salas, Historia de la asistencia social en España (Madrid: CSIC, 1958), 71-73.

14. Para el análisis de este debate todavía sigue vigente la introducción, excepcionalmente extensa y completa, llevada a cabo por Michel Cavillac a la obra de Cristóbal Pérez de Herrera, Amparo de pobres (Madrid: Clásicos Castellanos, Espasa Calpe, 1975).
} 


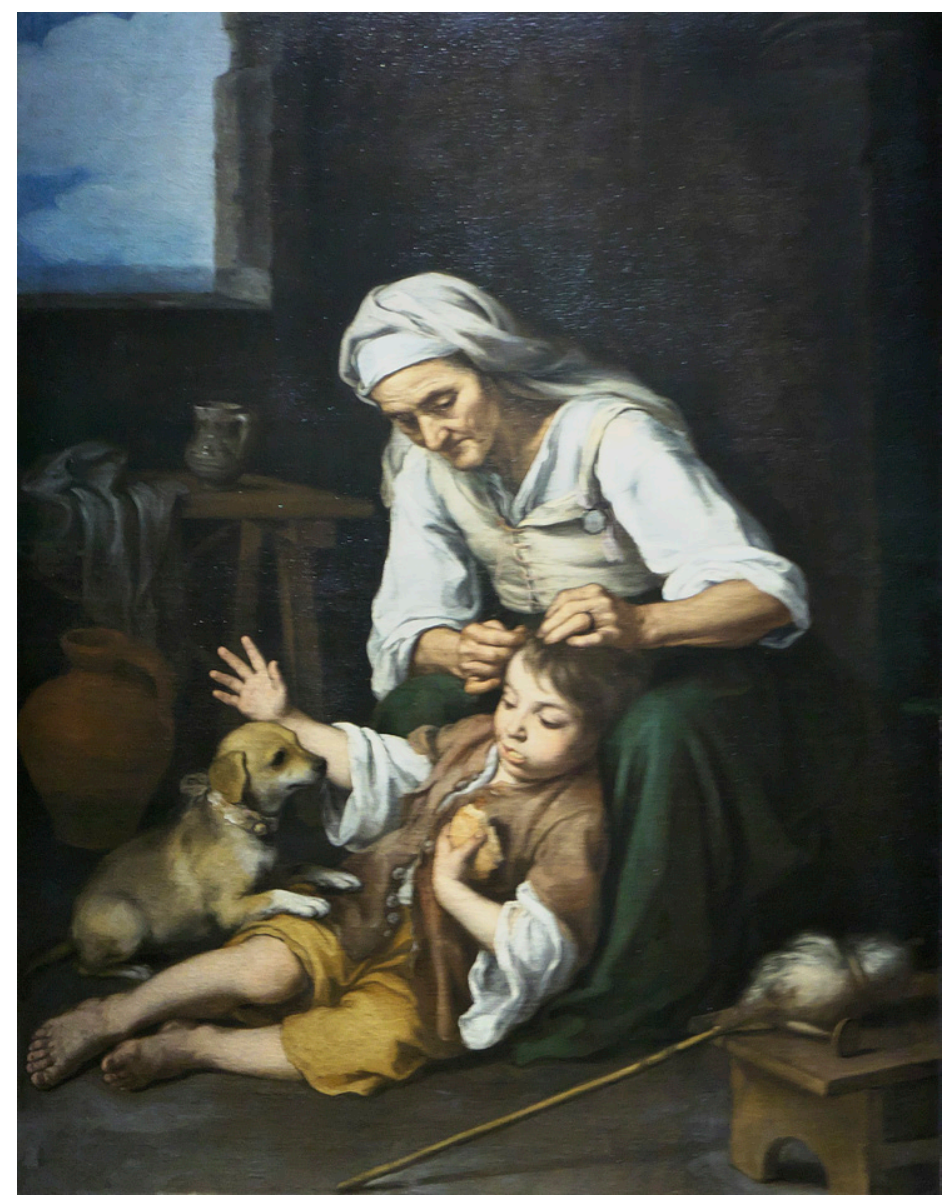

Fig. 4. Bartolomé Esteban Murillo, Vieja despiojando a un niño, 1660-1670. Óleo sobre lienzo, 147,5 × $113 \mathrm{~cm}$. Alte Pinakothek, Múnich. (Fotografía de José Luis Filpo Cabana, disponible en Wikimedia Commons, https://bit.ly/2xz0UxN).
España no iba a quedar al margen en la disputa. Juan Luis Vives, primer tratadista que aborda la problemática de la pobreza en términos sociológicos en su De subventione pauperum, no solo llega a afirmar que la limosna es insuficiente, sino también perniciosa. Por su parte, frente a este criterio erasmista y renovador, fray Domingo de Soto contraponía su teoría conservadora en su Deliberación de la causa de los pobres. Para él la libertad del mendigo es un derecho sagrado: "Si al rico por injuriarle le quitáis parte de su hacienda, quédale otra parte con que sustente la vida; empero al pobre, quien le quita el poder de pedir limosna, le quita no menos que la vida." 15

\footnotetext{
Sin la vista de los pobres, recogidos en hospitales, las limosnas [asegura nuestro teólogo] vendrían a disminuirse considerablemente, tan grande en la diferencia que hace pedir al mismo pobre para remediar su propia necesidad, o pedir un rico para cumplir las necesidades del Pobre. ${ }^{16}$
}

Para él la beneficencia es una cuestión de conciencia, no un problema político. Y de su teoría beberían décadas más tarde personajes como Miguel de Mañara.

Sin embargo en España la crisis del capitalismo castellano, su fracaso, sitúa la posición del debate en límites irreconciliables. En nuestro país la mano de obra es escasa y la más cara de Europa. La industria de la lana, el campo, la economía, precisan mano de obra. Y si algo sobra en la sociedad de momento son holgazanes y pobres fingidos. Toda una masa de población que encuentra el espejo donde mirarse en las ociosas élites del estamento nobiliario. El desprecio al trabajo era un patrimonio compartido tanto por la nobleza como por la picaresca.

Las Cortes de Castilla llevan décadas intentando, sin éxito, afrontar este problema. Los municipios procuran poner coto a una situación de farsa pobreza tan endémica como perniciosa. Sin embargo el proyecto favorable a la prohibición de la mendicidad acaba considerándose como una proposición herética en la

15. Domingo de Soto, Deliberación en la causa de los pobres (Madrid: Instituto de Estudios Políticos, 1965$), 54$. 16. Soto, 114-16. 
segunda mitad del XVI, algo inspirado en las ideas erasmistas o luteranas procedentes de la Europa del Norte.

Se refuerza la figura carismática y la ejemplar labor del santo limosnero. Tomás de Villanueva (1488-1555) reparte la casi totalidad de los 18.000 ducados de renta de su sede de Valencia en limosnas: 3.000 dona a su arzobispo antecesor, 2.000 entrega para escuelas de hijos de moriscos, 10.000 para alivio de pobres y enfermos. Se cuenta que unos 500 pobres acudían a diario a palacio para obtener socorro y pitanza. Podríamos citar a otras figuras fundamentales como la de san Juan de Dios (1485-1550), fundador de la Orden Hospitalaria. Recordemos que ambos santos serían representados por Murillo.

¿Pero es lo mismo un pobre que un pícaro? Dentro de esta dicotomía vamos a ver cómo aparecen nuevas y vigorosas aportaciones como las del canónigo catalán Miguel de Giginta, quien somete a las Cortes reunidas en Madrid en 1575 su Tratado de remedio de pobres. Giginta no es partidario de dictar leyes que coarten la libertad del menesteroso. Es más, se muestra así de contundente: "los que de aquesta comodidad

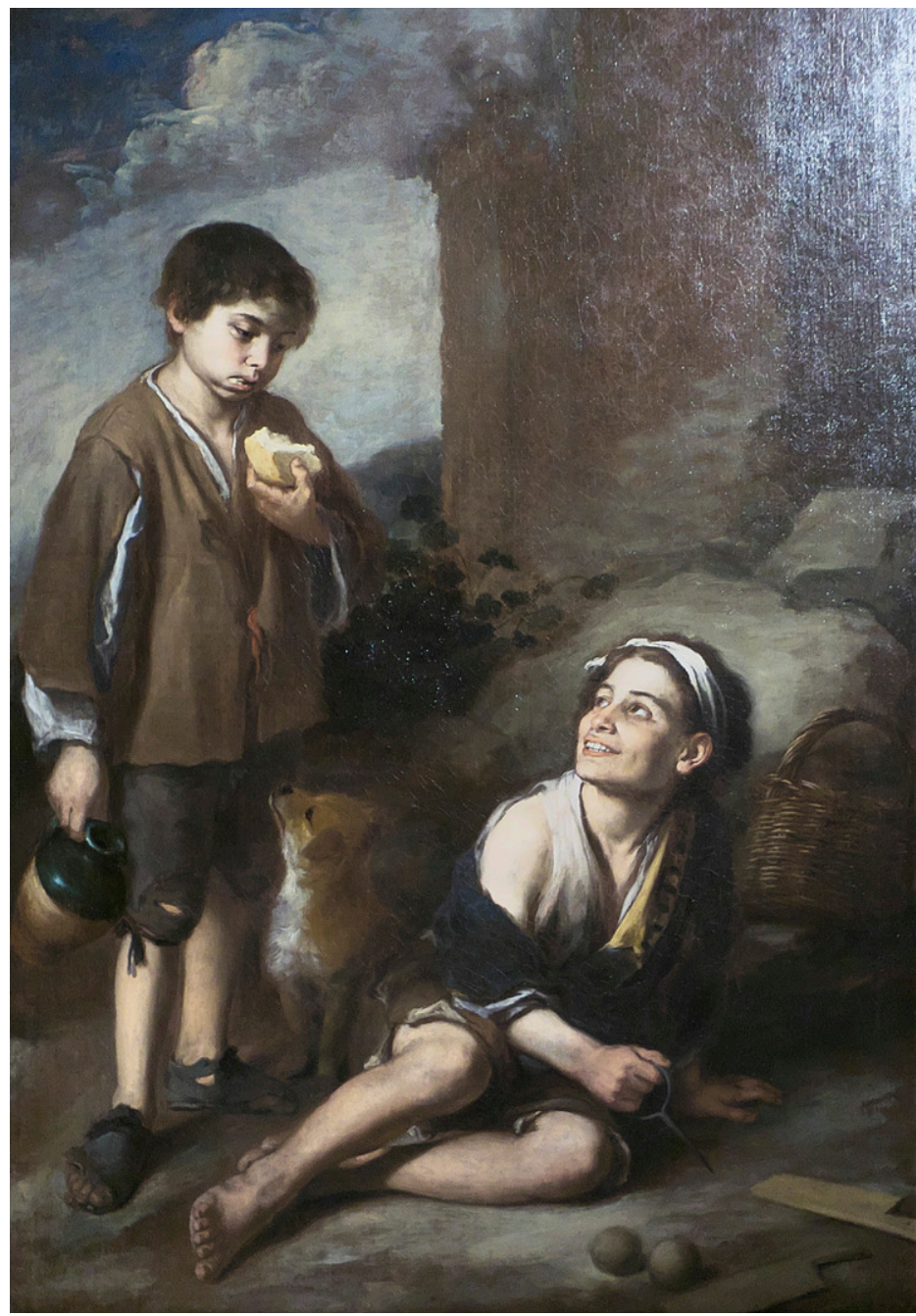

Fig. 5. Bartolomé Esteban Murillo, Invitación al juego de la argolla, 1665-1670. Óleo sobre lienzo, 165,2 x 110,5 cm. Dulwich Picture Gallery, Londres. (Fotografía de José Luis Filpo Cabana, disponible en Wikimedia Commons, https://bit.ly/2QQLYlt). no quisieren gozarse vayan o tomen otro arbitrio de Vida." La comodidad a la que se refiere es la creación en cada ciudad de una casa de misericordia donde poder ser acogida tanta caterva de pobres. Propone una casa ligera y barata siguiendo el modelo del hospital Reyes Católicos. Pero su valoración moral de esta población marginal y ociosa no se presta a dudas:

Si bien conocieseis a los ciegos... ellos y los otros viven todos amancebados y de más manera, haciendo mil perdiciones donde se juntan cada uno con la suya, trocando a veces las propias mujeres a su antojo... Son tan interesados que no hay embuste que no inventen para sacaros el dinero de la bolsa. Hacense mil llagas fingidas, entretienense en dólar sin curar engaños. Y algunas mendigas, para no perder el interés de este y de otros vicios, haciéndose preñadas, como lo están lo más del tiempo, procuran de mal parir para ir libres, y si todavía paren, luego los padres rompen los brazos o piernas a los niños, o los ciegan, para ganar con ello en cuanto les viven y dejarles para después con renta perpetua. ${ }^{17}$

17. Miguel Giginta, Tratado de remedio de pobres (Barcelona: Ariel Historia, 2000), 73. 


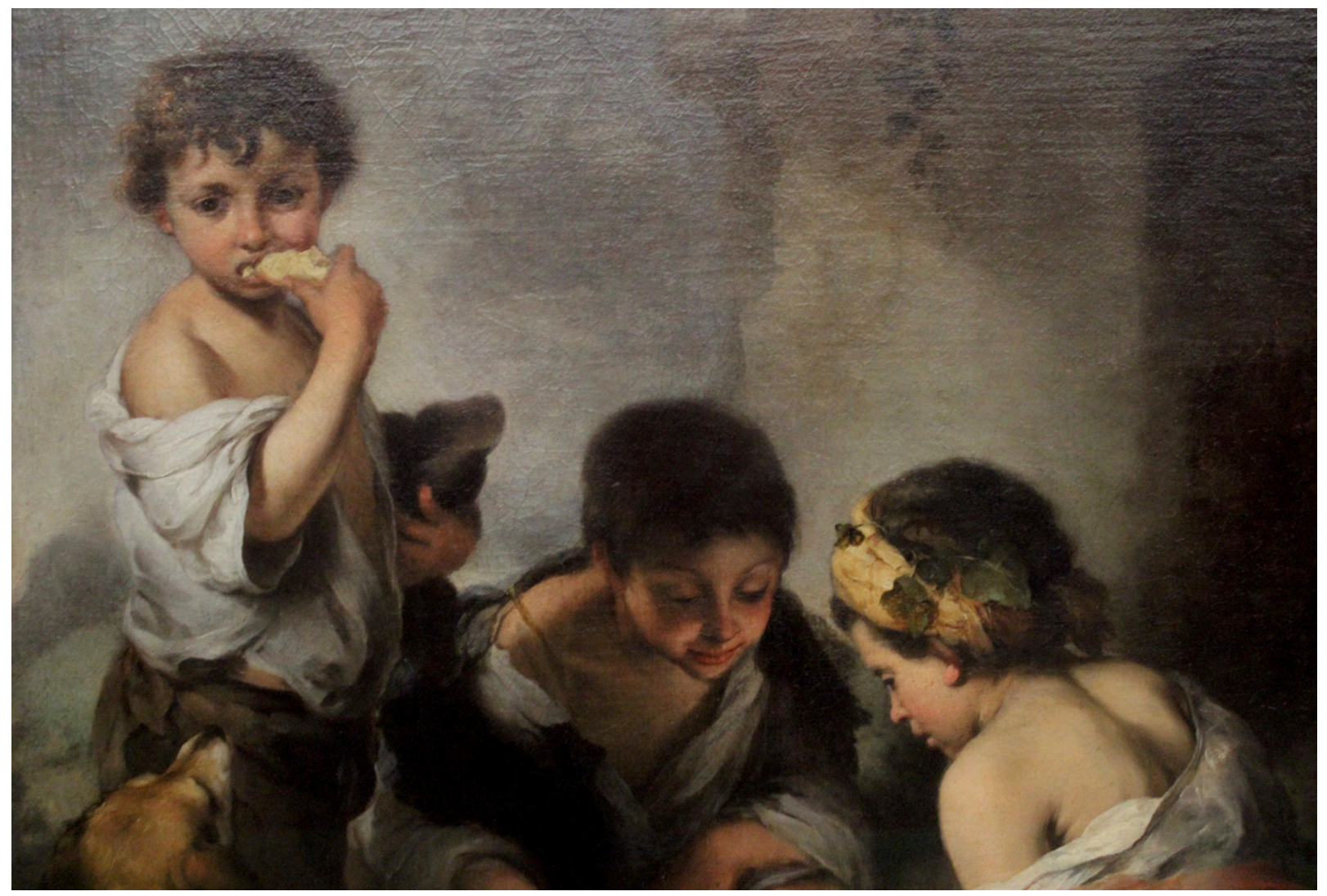

Fig. 6. Bartolomé Esteban Murillo, Niños jugando a los dados (detalle), 1665-1670. Óleo sobre lienzo, 140 x $108 \mathrm{~cm}$. Alte Pinakothek, Múnich. (Fotografía de Miguel Hermoso Cuesta, disponible en Wikimedia Commons, https://commons.wikimedia.org/wiki/File:Dados_Murillo_Munich_04.jpg ).

Hay que hacer notar que entre 1575 y 1586 son abiertos en ciudades como Madrid, Toledo, Granada o Barcelona los primeros centros de acogida "o recogida" de tantos desheredados.

Después de algunos ańos de bonanza en la última década del XVI asistimos a un recrudecimiento de la crisis económica y social en Castilla. En las ciudades la miseria hace aumentar de un modo alarmante la prostitución femenina. El número de expósitos abandonados en las calles o en las puertas de las iglesias se dispara. El porcentaje de pobres llega casi hasta duplicarse.

Ante este avance de la calamidad surge la lúcida propuesta del bachiller Cristóbal Pérez de Herrera, de clara tendencia mercantilista. Su plan consistía en la apertura en las principales cincuenta aglomeraciones urbanas de España de una casa de pobres o albergue donde vivir y dedicarse a alguna ocupación productiva. Estos pobres mendigos tendrían la obligación de presentarse en estos centros a una hora determinada para ser inscritos en un registro. Y solo los pobres legítimos, una vez examinados por cuatro personas, recibirían certificado renovable cada año junto a un distintivo con las armas de la ciudad y una imagen de Nuestra Señora. Solo así quedarían facultados para ejercer la mendicidad. 


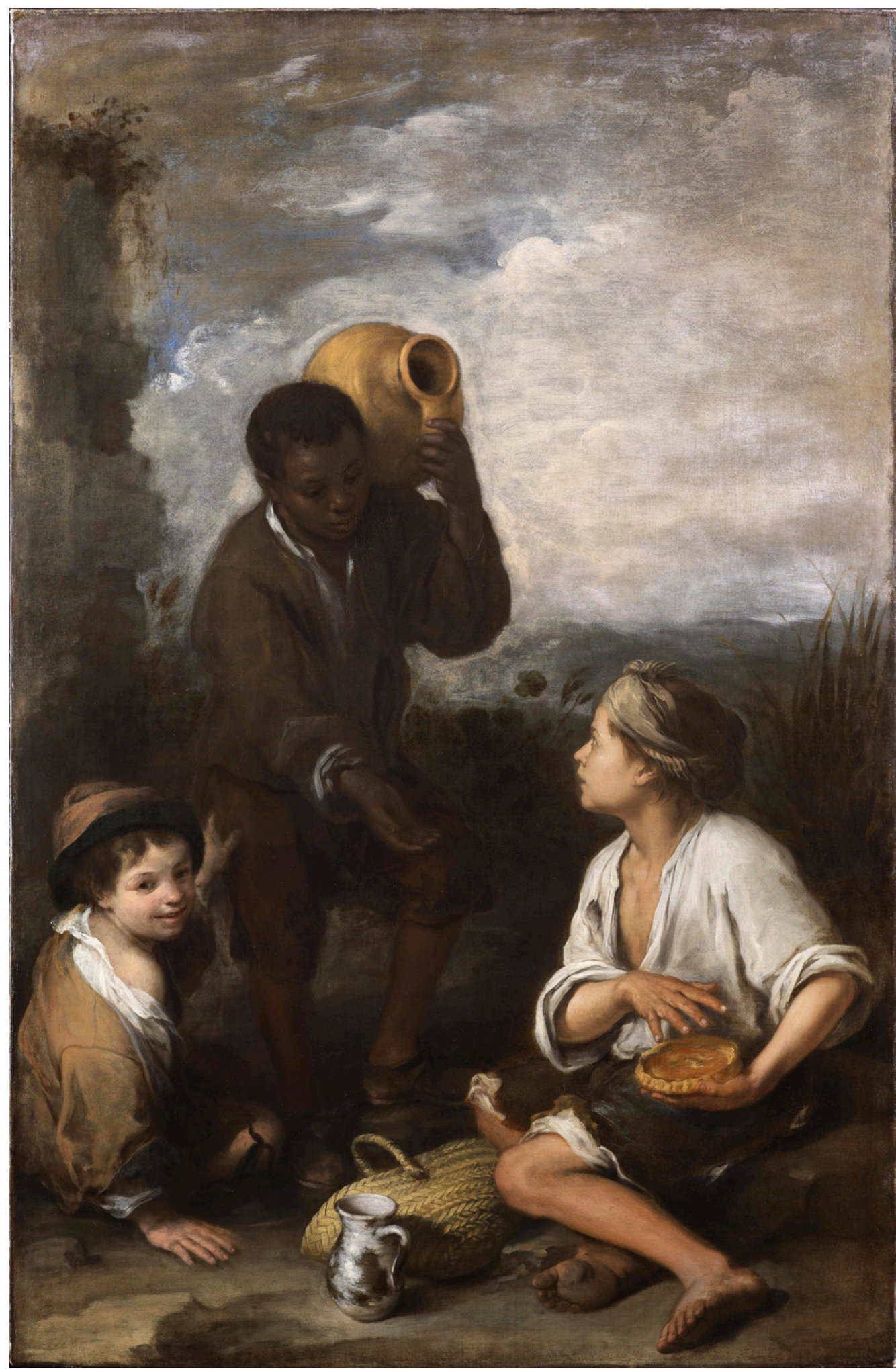

Fig. 7. Bartolomé Esteban Murillo, Tres muchachos, ca. 1670. Óleo sobre lienzo, 168,3 x 109,8 cm. Dulwich Picture Gallery, Londres. (Fotografía de dominio público, disponible en Wikimedia Commons, https://bit.ly/3bya9No). 
No se trataba de una medida represiva, tampoco un internamiento forzoso; simplemente se trataba de imponer un control geográfico y legal al grave problema de tanto pobre impostor, de tanto vago improductivo, de tanta prostitución callejera, de tanto nińo abandonado a su suerte y condenado a ser carne de horca. Pérez de Herrera, a diferencia de Vives y en consonancia con Soto, se muestra en contra de los encerramientos forzosos de los mendigos. Aboga por el derecho de los pobres a la limosna siempre que estos no sean impostores. Pero avisa: en el momento de la publicación de su tratado existen 150.000 mendigos falsos. Luego, en 1608, ya en tiempos de Felipe III, aumentará esta cifra a 500.000.

En una ciudad como Sevilla, la urbe más populosa y dinámica de la Península esta explosiva situación de contraste entre opulencia e infame pobreza adquiría en las últimas décadas del XVI tintes de desmesura. En 1595 Francisco de Ariño nos describe la llegada a la ciudad del mayor tesoro venido de América. ${ }^{18}$ Justo dos años más tarde este mismo cronista nos describe el "primer registro de pobres" llevado a cabo en la urbe por su Concejo. El espectáculo —nos cuenta— "fue el mayor teatro que jamás se ha visto."

La reforma hospitalaria llevada a cabo en Sevilla más que aliviar la situación en su intento de racionalización la agravó al reducir estos benéficos establecimientos, en manos de la Iglesia, hermandades y casas nobiliarias, a tan solo dos. En muchos de los desaparecidos — según denunciaba el mayordomo de los Jurados del Cabildo- "se recogían pobres y mendigos, viejos, lisiados e impedidos para poder andar por las calles... y por no tener donde acogerse se mueren por las calles y resultan otros muchos inconvenientes contra caridad..." 19

Peor suerte tuvieron infinidad de nińos abandonados, "que son tantos que suelen llegar a trescientos y se sustentan por ahora con solo limosnas que piden." ${ }^{20}$ Alonso de Morgado, en su Historia de Sevilla publicada en 1587, habla de la existencia de la Casa Cuna, provista por el Cabildo de la Santa Iglesia Catedral para recoger "los nińos que ordinariamente se echavan por las puertas de las iglesias, y por cualquier otra parte de toda Sevilla." Pocas veces su número baja de 140, "y en día solo de cada un año suelen prohijarse de sesenta nińos arriba." ${ }^{11}$ Este número no iba a descender, experimentando un crecimiento espectacular a mediados del siguiente siglo.

Existía en la ciudad una casa-hospital de niños perdidos, patrocinada por la Hermandad del Santísimo Niño Perdido:

que de aver en esta ciudad grandísimo número de Niños y Nińas huérfanos y forasteros y no tener quien los ampare, ni gobierne, andaban vagando ociosos, aprendiendo vicios, como jurar, jugar, blasfemar, y aún hurtar, y cometer otros graves delitos, y las Nińas a ser deshonestas. ${ }^{22}$

En 1593 nuevas denuncias de diputados ante el Cabildo de la Hermandad del Niño Perdido, tras ser esta esta clausurada por falta de recursos económicos, volvía a poner en dedo en la llaga sobre la situación:

\footnotetext{
18. Francisco de Ariño, Sucesos de Sevilla de 1592 a 1604 (Sevilla: Rafael Tarascó y Lassa, 1973), 45-47.

19. Francisco Rodríguez Marín, "Introducción," en Rinconete y Cortadillo, Miguel de Cervantes Saavedra (Madrid: s.n., 1920$), 50$.

20. Rodríguez Marín.

21. Alonso de Morgado, Historia de Sevilla: en la qual se contienen sus antigüedades, grandezas y cosas memorables... (Sevilla: Imprenta de Andrea Pescioni y luan de Leon, 1587), 319.

22. Antonio Domínguez Ortiz, La Sevilla del siglo XVII (Sevilla: Universidad de Sevilla, 1984), 372-73.
} 
porque la ciudad, calles y plazas están llenas de muchachos pequeños que andan perdidos pidiendo limosna y muriendo de hambre... y otros amaneciendo muertos de hielo. ${ }^{23}$

Más desoladora es, si cabe — nos describe de nuevo el informe de los diputados—, la situación de los niños aquejados de enfermedades contagiosas, porque "a los tiñosos aborrece el pueblo por ser tan asquerosos y no sólo no le quieren meter en sus casas porque ni aún cuando les dan limosna llégales la mano.”24

Este era el panorama que ya ofrecía la Nueva Babilonia en los últimos años del XVI. Pero la llegada de Felipe III, aunque parezca imposible, aún empeoró la situación. El recrudecimiento de la mentalidad nobiliaria del momento, el rechazo de cualquier tipo de propuesta de modernización llevado a cabo por arbitristas como Pérez de Herrera, fue definitivamente abandonado. Triunfaba la ortodoxia ideológica más añeja y reaccionaria al tiempo que empeoraba por agotamiento la situación económica y social.

Para la época de Murillo la sociedad castellana, sus élites nobiliarias y eclesiásticas, olvidadas viejas veleidades modernizadoras de dudosa ortodoxia para ellos, ya permanecía anclada en el más puro conservadurismo contrarreformista. Y la solución al problema de la pobreza, tan dramático como a veces fingido, quedaba solo en manos de la caridad individual. En la Sevilla de Murillo la pobreza, en sus múltiples y lacerantes versiones, qué duda cabe que podía provocar una visión cuanto menos inquietante entre la población no indigente, inquietante y ambigua.

La imagen del pobre produce rechazo entre las gentes ante la posible contaminación de lacras morales o físicas. En nuestra novela picaresca tal vez el adjetivo más usado para describir al pobre es el de "asqueroso." Marcos de Obregón, que se ha acogido en la parroquia de Omnium Sactorum para evitar la justicia, intenta la treta de disfrazarse de mendigo y de esta guisa — nos cuenta- "echose entre unos pobres muy asquerosos que estaban pidiendo limosna.” Pero, frente a este hecho incuestionable, solo queda la visión a la que nos obliga la moral de nuestra Santa Iglesia: la condescendencia piadosa y la caridad fraternal.

Anulado cualquier intento de reforma racional desde el punto de vista productivo y moralizante, debilitado el viejo sistema asistencial de beneficencia, mediado ya el XVII, la solución al problema del pobre tan solo depende de la conciencia personal de cada cristiano. Había que devolver la santidad a la imagen del pobre, aunque este no siempre lo pareciera. Este nuevo concepto lo sintetizaba con contundencia Juan de Zabaleta:

El tratar a un pobre sin cortesía es desacato que se hace al Rey de los reyes: porque el pobre que pide es un hombre enviado del cielo, a que le ruegue de parte de Dios que haga una buena obra. Al que envía el recado ofende quien desestima al recaudador. El no darle limosna es villanía infame, porque es ponerse de parte de la necesidad su enemiga, que es la parte más fuerte. ${ }^{25}$

El pobre es vehículo de redención para los misericordiosos. Y estos alcanzarán la misericordia.

\footnotetext{
23. Juan Ignacio Carmona García, El sistema de hospitalidad pública en la Sevilla del antiguo régimen (Sevilla: Excma. Diputación Provincial, 1979$), 114$. 24. Giginta, Tratado de remedio de pobres, 115.

25. Ludwig Pfandl, Cultura y costumbres del pueblo español de los siglos XVI y XVII: introducción al estudio del Siglo de Oro (Barcelona: Casa Araluce, 1959$), 146$.
} 


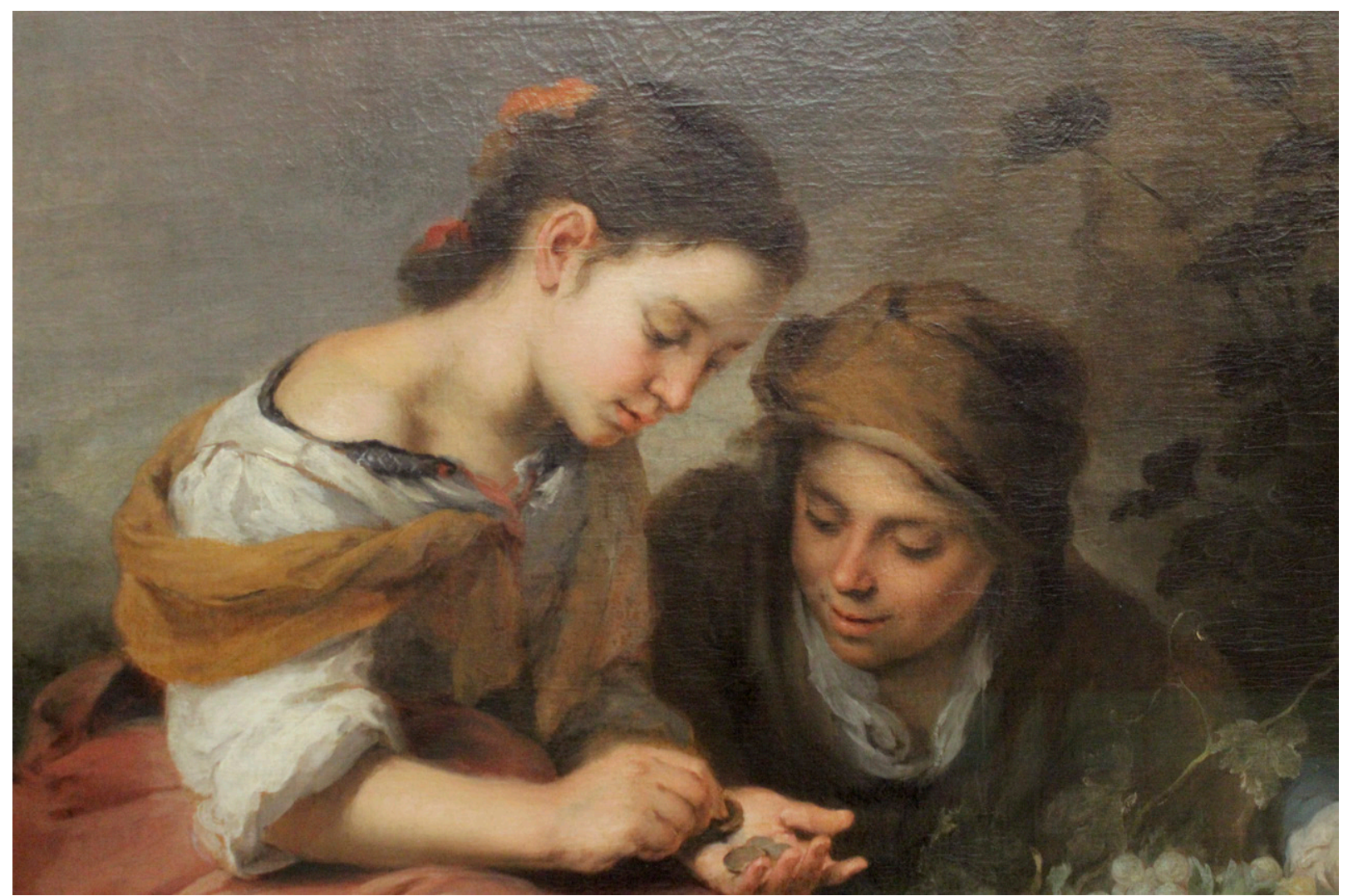

Fig. 8. Bartolomé Esteban Murillo, Vendedores de fruta (detalle), 1670-1675. Óleo sobre lienzo, 149 × $113 \mathrm{~cm}$. Alte Pinakothek, Múnich. (Fotografía de Miguel Hermoso Cuesta, disponible en Wikimedia Commons, https://commons.wikimedia.org/wiki/File:La_vendedora_de_fruta_Murillo_04.jpg ).

Ninguna figura en la Sevilla ya de la segunda mitad del Seiscientos conseguirá el grado de exaltación apostólica, carismática y hasta un punto paranoica, de don Miguel de Mañara. Su pensamiento queda perfectamente definido por la lectura de su obra y, sobre todo, por el análisis del programa simbólico e iconográfico que él mismo diseñara para su iglesia de la Santa Caridad. Para ilustrar epigráficamente todo su discurso, para el vértice central del pavimento del crucero Mañara elige un proverbio, el 19, que es piedra angular de toda su filosofía: Faeneratur Domino qui miseratur pauperis (Desdichado aquél, Señor, que no tiene misericordia de los pobres). ${ }^{26}$

Por ello cuando contesta por carta a un amigo que le pedía su parecer sobre la reclusión de los pobres en Madrid en un centro del Ave María, después de hacer un repaso argumental no exento de ironía sobre los textos sagrados, la Patrística y la hagiografía, habla de políticos — cuyo Dios es Maquiavelo—, "pues cárcel es donde no hay libertad... preciosísima joya." Y añade: “¿La vista de los pobres queréis esconderla para que se apague en vuestras almas ese poco calor que teníais de caridad?”27

\footnotetext{
26. Arsenio Moreno Mendoza, "La iconografía de la iglesia sevillana del Hospital de la Santa Caridad. Nuevas anotaciones," Cuadernos de Arte e Iconografía (Madrid) 13, no. 26 (2004): 491-511.

27. Juan de Cardenas, Breve relacion de la muerte, vida y virtudes del venerable caballero D. Miguel de Mañara Vicentelo de Leca, caballero del Orden de Calatrava, Hermano Mayor de la Santa Charidad (Sevilla: Imprenta Castellana, y Latina de Diego Lopez de Haro, 1703), 97-99.
} 
Esta visión santificadora de la pobreza encontraría en la pintura de Murillo su más perfecta expresión. Desde la representación de San Diego de Alcalá dando de comer a los pobres pintada para el claustro chico del convento de San Francisco de Sevilla hasta su Santo Tomás de Villanueva dando limosna, pasando por sus inmortales niños callejeros, el pobre adquiere un perfil beatífico. Sus mendigos adultos son graves, reverentes, conscientes de su papel en el cuerpo místico de la Iglesia. Sus niños, sucios y harapientos, son inocentes y hermosos. Niños como aquel que señala y se ríe de la vieja avarienta que protege su plato de migas del WallrafRichartz Museum de Colonia, pues la ausencia de caridad, el egoísmo, no es pecado exclusivo de los ricos.

Esta, como dijimos en un principio, es una visión complaciente, yo diría que autocomplaciente de la pobreza y del pobre. La pobreza no deja de ser un concepto abstracto, el pobre, en cambio, es un sujeto concreto.

\section{Referencias}

Angulo Íniguez, Diego. "Murillo, su vida y su obra." En Bartolomé Esteban Murillo 1617-1682, coordinado por Manuela B. Mena Marqués y M.a Isabel de Alzaga de Serra, 55-75. Madrid: Museo del Prado, 1982. Publicado en conjunto con una exhibición del mismo título, organizada y presentada en el Museo del Prado en Madrid, 8 de octubre de 1982-12 de diciembre de 1028, y en la Royal Academy en Londres, 15 de enero de 1983-27 de marzo de 1983.

Ariño, Francisco de. Sucesos de Sevilla de 1592 a 1604. Sevilla: Rafael Tarascó y Lassa, 1973.

Bennassar, Bartolomé. La España del Siglo de Oro. Barcelona: Ed. Crítica, 2017.

Brown, Jonathan. "Murillo, pintor de temas eróticos: Una faceta inadvertida de su obra." Goya: Revista de Arte, no. 169-171 (1982): 35-43.

Cardenas, Juan de. Breve relacion de la muerte, vida y virtudes del venerable caballero D. Miguel de Mañara Vicentelo de Leca, caballero del Orden de Calatrava, Hermano Mayor de la Santa Charidad. Sevilla: Imprenta Castellana, y Latina de Diego Lopez de Haro, 1703.

Carmona García, Juan Ignacio. El sistema de hospitalidad pública en la Sevilla del antiguo régimen. Sevilla: Excma. Diputación Provincial, 1979.

Cavillac, Michel. "Introducción." En Amparo de pobres, Cristóbal Pérez de Herrera. Madrid: Clásicos Castellanos, Espasa Calpe, 1975.

Ceán Bermúdez, Juan Agustín. Diccionario Histórico de los más ilustres profesores de las Bellas Artes en España (Año de 1800). T. 2. Madrid: Imprenta de la Viuda de Ybarra, Edición facsímil, 1965.

Domínguez Ortiz, Antonio. La Sevilla del siglo XVII. Sevilla: Universidad de Sevilla, 1984.

García Felguera, María de los Santos. La Fortuna de Murillo. Sevilla: Diputación Provincial, 1989.

Giginta, Miguel. Tratado de remedio de pobres. Barcelona: Ariel Historia, 2000.

Jiménez Salas, María. Historia de la asistencia social en España. Madrid: CSIC, 1958.

Jordan, William B., y Peter Cherry. El bodegón español de Velázquez a Goya. Madrid: El Viso, 1995.

Levine, David A., y Ekkehard Mai. I Bamboccianti: Niederländische Malerrebellen im Rom des Barock. Köln: Wallraf-Richartz Museum, 1991.

Moreno Mendoza, Arsenio. Mentalidad y pintura en la Sevilla del Siglo de Oro. Madrid: Electa, 1997. 
---. "La iconografía de la iglesia sevillana del Hospital de la Santa Caridad. Nuevas anotaciones." Cuadernos de Arte e Iconografia (Madrid) 13, no. 26 (2004): 491-511.

Morgado, Alonso de. Historia de Sevilla: en la qual se contienen sus antigüedades, grandezas y cosas memorables... Sevilla: Imprenta de Andrea Pescioni y Iuan de Leon, 1587.

Navarrete Prieto, Benito. Murillo y las metáforas de la imagen. Madrid: Cátedra, 2017.

Palomino de Castro y Velasco, Antonio. El museo pictórico y escala óptica. Práctica de la pintura, en que se trata del modo de pintar á el olio, temple y fresco, con la resolucion de todas las dudas que en su manipulacion pueden ocurrir, y de la perspectiva común, la de techos, ángulos, teatros, y monumentos de perspectiva, y otras cosas muy especiales, con la direccion y documentos para las ideas ó asuntos de las obras de que se ponen algunos ejemplares. Vol. 2. Madrid: Imprenta de Sancha, 1797.

Pérez Sánchez, Alfonso Emilio. "Algunas obras de 'Monsu Bernardo'”. Archivo Español de Arte 34, no. 134 (1961): 141-44.

Pfandl, Ludwig. Cultura y costumbres del pueblo español de los siglos XVI y XVII: introducción al estudio del Siglo de Oro. Barcelona: Casa Araluce, 1959.

Rodríguez Marín, Francisco. “Introducción.” En Rinconete y Cortadillo, Miguel de Cervantes Saavedra. Madrid: s.n., 1920.

Soto, Domingo de. Deliberación en la causa de los pobres. Madrid: Instituto de Estudios Políticos, 1965.

Wind, Barry. Studies in Genre Painting: 1580-1630. New York: New York University, 1973. 